\title{
Salivary Cortisol and a-Amylase Production at Awakening is Associated with Positivity (POS) Levels in Healthy Young Subjects
}

\author{
Vittorio Pasquali ${ }^{1}$ (i) $\cdot$ Cristina Mihaela Ghiciuc $^{2} \cdot$ Valeria Castellani $^{1}$. \\ Gian Vittorio Caprara ${ }^{1} \cdot$ Guido Alessandri ${ }^{1}$. Raffaele D'Amelio ${ }^{3}$. Vincenzo Ziparo ${ }^{4}$. \\ Fabio Scarinci ${ }^{5}$. Francesca Romana Patacchioli ${ }^{5,6}$
}

Accepted: 15 September 2020

(c) The Author(s) 2020

\begin{abstract}
A large variety of positive outcomes including social adjustment, psychological well-being and health, have been recently closely associated with positivity (POS). On the assumption that differences in the POS degree might be associated with different individual neuroendocrine assets that enables people to cope effectively with stress, the present study examined the association between POS, salivary cortisol and $\alpha$-Amylase ( $\alpha$-Amy) production in a group of healthy male volunteers university students, respectively scoring high (POS-H, $N=10)$ and low (POS-L, $N=10$ ) in POS. Participants were selected from a larger sample of 300 students of the Medical School at Sapienza University of Rome on the basis of their positivity level: POS was analysed and the upper and lower $25 \%$ were invited to participate in this new study. The findings report a distinct salivary cortisol and $\alpha$-Amy production in the study population: in comparison to the POS-H group, the POS-L subjects presented a lower salivary cortisol awake response (CAR) and a flattened $\alpha$-Amy production at 30 and $60 \mathrm{~min}$ after awakening. In addition, salivary cortisol and $\alpha$-Amy areas under the curve (AUCs), which were calculated as indicators of the two subclinical biomarkers production during the first hour after awakening, resulted significantly lower in the POS-L group in comparison to the POS-H group. Further studies on larger and different populations are needed to definitively confirm that the different cortisol and $\alpha$-Amy secretion patterns between POS-H and POS-L individuals is associated with a potentially better capacity to preserving an adequate quality of life in individuals being equipped with a system apparently able to better respond to external and/or internal stimuli. Lastly, a better understanding of the biological correlates of POS is crucial to design psychological interventions able to take advantage of individuals' assets and thus to integrate and strengthen the efficacy of traditional medications.
\end{abstract}

The author Fabio Scarinci participated in this study as student of the XXXII Cycle of the Doctorate in Pharmacology and Toxicology, held at the Department of Physiology and Pharmacology_Sapienza University of Rome.

Vittorio Pasquali

vittorio.pasquali@uniroma1.it

Extended author information available on the last page of the article 
Keywords Positive orientation (POS) - Salivary cortisol awakening response (CAR) .

Salivary $\alpha$-amylase awakening response $\cdot$ Salivary cortisol AUC $\cdot$ Salivary $\alpha$-amylase AUC

\section{Introduction}

A growing body of research has focused on the roles that individual differences in personality may play in promoting health and in moderating vulnerability to adversities and illness. Interest in the positive features of individual functioning linked with adjustment and resilience to life challenges has received continued attention throughout the history of psychology (Seligman and Csikszentmihalyi 2000). Several scholars have independently explored, at different times, the importance of approaching life experiences with a positive view. Scheier and Carver (1992) were among the first to propose positive thinking, or individuals' basic confidence in their future, as the key for understanding the different ways in which humans approach and react to life. Later, Diener and colleagues (2000) suggested that people evaluate their lives on the basis of their basic level of positivity. Moreover, positive affect, i.e., the feelings that reflect a level of pleasurable engagement with the environment, has been associated with physical health (Pressman and Cohen 2005). Among the individual characteristics that have been previously associated with a variety of positive outcomes are self-esteem (Baumeister et al. 2003), optimism (Carver et al. 2010) and life satisfaction (Pavot and Diener 2008). A large number of studies have corroborated the idea that positivity (POS) represents a common latent factor underlying self-esteem, life satisfaction, and dispositional optimism in diverse samples and cultures (Caprara et al. 2010a). Twin studies have shown that heritability accounts for approximately $50 \%$ of the variance of this latent dimension, whereas unshared environment accounts for the remaining percentage (Fagnani et al. 2014). Further studies have provided evidence of the stability of POS over the course of development and of its potential positive effect on people's lives across diverse domains of functioning, including health, work performance, psychological well-being, and social adjustment (Alessandri et al. 2012; Fagnani et al. 2014). Of interest, little residual variance was explained in the above outcomes by self-esteem, life satisfaction, and optimism once their common component was considered (Alessandri et al. 2015).

POS likely plays an important biological function because thinking that life is worth living and that the future is promising allows people to cope with adversities and losses in life (Caprara et al. 2009). Accordingly, individual differences in POS can play a fundamental role in ensuring the best balance between conservative and aversive adaptive tendencies (Caprara et al. 2012). High POS can be beneficial to well-being as it helps individuals to draw the best from their potential and from situational opportunities (see Caprara et al. 2010b, c, 2012).

Research findings have preliminarily attested to the protective function that POS may exert at the very basic level of the immune system by countering the disturbing effect of stress (Caprara et al. 2017) and contributing to maintaining an adequate quality of life even under condition of severe illness (Caprara et al. 2016). Daily hassles and life events may result in allostatic overload and lead to erratic neuroendocrine responses. This situation led us to hypothesize that differences in POS degree might be associated with different neuroendocrine assets of the hypothalamic-pituitary-adrenal (HPA) axis and sympathetic adrenal-medullar (SAM) system activities.

Measurements of salivary cortisol and salivary $\alpha$-amylase ( $\alpha$-Amy) as biomarkers of the HPA axis and SAM system activities, respectively, are increasingly used for noninvasive 
monitoring of the human body's neuroendocrine response to life challenges under various physio-pathological conditions (Bosch et al. 2011; Cozma et al. 2017; Delle Chiaie et al. 2013; Ghiciuc et al. 2011, 2013; Nater et al. 2006, 2013; Nater and Rohleder 2009; Patacchioli et al. 2015; Schumacher et al. 2013; Simeoni et al. 2011).

The cortisol awakening response (CAR) reflects the increase of cortisol concentration that occurs over the first hour after waking (Pruessner et al. 1997; Stalder et al. 2016). The CAR is a useful index of HPA axis function - an indicator of the major endocrine stress response system - and has been found to be reduced among people with posttraumatic stress, fatigue symptoms, burnout, or exhaustion. A lower CAR has also been described in depressive patients with a higher risk of developing chronic depression (Chida and Steptoe 2009; Vreeburg et al. 2009, 2010; Proulx et al. 2017).

Salivary $\alpha$-Amy, the secretion of which is under strong neurohormonal control, has been proposed as a "cortisol-like" noninvasive and easily obtainable marker of SAM system modifications in basal conditions and under stress (Chatterton et al. 1996; Cozma et al. 2017; Li and Gleeson 2004; Wolf et al. 2008). Significant diurnal fluctuations in salivary $\alpha$-Amy have been observed that are opposite to those of cortisol, with low values at awakening (Nater et al. 2007) and progressively significantly higher values over the day (Ghiciuc et al. 2011; Nater et al. 2007; Yamaguchi et al. 2006), confirming that these two systems are distinct (Wolf et al. 2008).

Based on this assumption, the present study examined the associations among POS, salivary cortisol, and $\alpha$-Amy production in a select group of healthy male university student volunteers who had high (POS-H) or low (POS-L) POS scores. Salivary CAR, salivary awakening $\alpha$-Amy levels, and area under the curve (AUC)s of salivary cortisol and $\alpha$-Amy production were measured at awakening and at 30 and 60 min thereafter under basal conditions.

\section{Methods}

\subsection{Study Population}

The participants were selected from a larger sample of 300 students of the Medical School at Sapienza University of Rome on the basis of their positivity level. The study protocol was approved by the research ethics committee of the Azienda Ospedaliera Sant'Andrea (CE n. 353/2012).

The participants received all measures by mail and returned them after completion. Experimenters informed the participants that their responses would be absolutely confidential and offered clarification regarding the variables measured. The eight-item POS scale, with 5-point Likert scales ranging from 1 (strongly disagree) to 5 (strongly agree) and a Cronbach's alpha of 0.79 (95\% confidence interval: $0.76,0.82)$, was used to select enrolled participants (Caprara et al. 2012).

Inclusion criteria were POS mean level $\geq 75^{\circ}$ percentile (POS-H) or POS mean level $\leq 25^{\circ}$ percentile (POS-L). In the a priori sample size calculation, we estimated that at least 7 subjects per group were required to detect a mean absolute difference of approximately $50 \%$ for the expected changes in salivary cortisol concentrations between the values measured at awakening and at 30 min later, with an $\alpha$ of $0.05, \beta=0.2$, and statistical power of $80 \%$. 
Only male participants were included in the present preliminary study to avoid the confounding of our dependent variables by sex-related factors (Kirschbaum et al. 1999). In addition, all the participants were medication-free. The subjects who met the inclusion criteria were contacted by phone and invited to participate in this study.

Ultimately, 10 POS-H (mean POS: 4.56 SD 0.23; mean age: 21.2 SD 1.3 range 20-23) and 10 POS-L (mean POS: 2.84 SD 0.32; mean age: 21.5 SD 1.3 range 19-24) Caucasian males agreed to participate in the subsequent session of the study, and written informed consent was obtained from all the participants during a preliminary informative meeting.

\subsection{Salivary Sampling Procedure; Salivary Cortisol and a-Amylase Measurement}

During the three days before the "saliva sampling day", the participants were asked to maintain a quiet resting state without engaging in any intense physical activity or receiving any significant psychological input. The diet was similar among the study population. The subjects were asked to avoid food, coffee or alcohol consumption, teeth brushing, smoking, and any physical exercise for 30 min prior to each saliva collection (Hackney and Viru 2008; Hanrahan et al. 2006).

After they completed the informed consent to participate in the study, the participants were instructed on how to collect their saliva at home using the Salivette sampling device (Sarstedt, Italy). All of the participants underwent three salivary collections: the saliva was collected at awakening and at 30 and 60 min thereafter. The participants were asked to store the samples in their home refrigerators and to deliver the samples to the laboratory on the day after collection. The saliva was recovered from the polyester swab devices by centrifugation at $3000 \mathrm{rpm}$ for $15 \mathrm{~min}$ (Gröschl et al. 2008). The salivary samples were immediately frozen at a temperature of $-20^{\circ} \mathrm{C}$ until they were analyzed.

Salivary cortisol was assayed on duplicate 25 - $\mu$ l samples using a commercial immunoenzymatic kit (DiaMetra, Italy). The inter- and intra-assay were $<10 \%$ and $<7 \%$, respectively, with a minimum detectable concentration of $0.5 \mathrm{ng} / \mathrm{ml}$. On the same sample, the salivary $\alpha$-amylase activity was quantified via a commercially available colorimetric kit (DiaMetra, Italy); the interassay coefficient variation was $<1.5 \%$, and the minimum detectable concentration of $\alpha$-amylase that could be distinguished from the blank standard at a $95 \%$ confidence interval was $2.5 \mathrm{U} / \mathrm{ml}$.

\subsection{Statistical Analysis}

All of the data are reported as the means \pm SEM unless otherwise specified. The statistical analyses and graphs were performed using SigmaPlot 11 (S x T.it, Italy) and Statistica 6 (StatSoft Inc.) software.

The GROUP, TIME, and GROUP $\times$ TIME effects on salivary cortisol and salivary $\alpha$-Amy diurnal trajectories measured in the study population were determined using the two-way ANOVA for repeated measures followed by the post hoc Tukey's test for multiple comparisons.

The salivary cortisol and salivary $\alpha$-Amy diurnal production were calculated from the area under the curve (AUC) of the salivary cortisol $(\mathrm{ng} / \mathrm{ml} / \mathrm{h})$ and the $\alpha$-Amy $(\mathrm{U} / \mathrm{ml} / \mathrm{h})$ calculated for each subject using the trapezoidal method, with respect to ground, for the three samples collected at awakening and at 30 and 60 min thereafter (Fekedulegn et al. 2007; Pruessner et al. 2003). The statistical significance was set at $p<0.05$. 


\section{Results}

\subsection{Characteristics of the Study Population}

No significant differences were detected between the two groups with respect to the population characteristics. The subjects had a similar mean age [POS-H: 21 (19-24 years); POS-L: 22 (20-27 years)]. The body mass index (BMI), which compares height to weight, indicated no detectable differences between the two groups in the study population (22.1 in POS-H subgroups and 22.5 in POS-L subgroups), with all the participants within the normal zone (Yumuk et al. 2015).

\subsection{Salivary Cortisol and a-Amylase Awakening Responses in the Study Population}

We hypothesized that POS-H and POS-L can be associated with distinct HPA axis as well as SAM system activities at awakening. The upper portion of Fig. 1 shows the mean levels \pm SE of salivary cortisol measured on the sampling day in the POS-H

Fig. 1 Salivary Cortisol and $\alpha$-Amylase Awakening Responses in the study population. Data are expressed as mean \pm SE. Post hoc Tukey's test for multiple comparisons: * and $* * p<0.01$ and $p<0.001$, respectively, vs awake; ${ }^{\#}$ and ${ }^{\# \#} p<0.05$ and $p<0.001$, respectively, versus POS-H
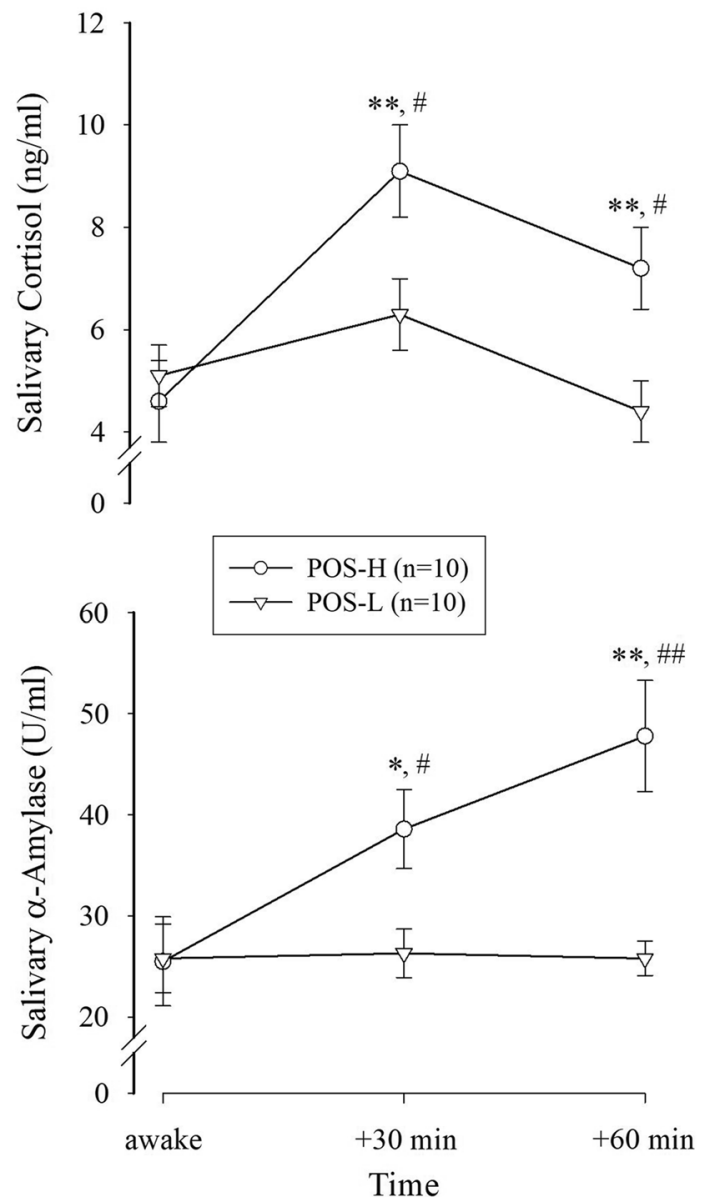
(awake: $4.6 \pm 0.8 \mathrm{ng} / \mathrm{ml} ;+30 \mathrm{~min}: 9.1 \pm 0.9 \mathrm{ng} / \mathrm{ml} ;+60 \mathrm{~min}: 7.2 \pm 0.8 \mathrm{ng} / \mathrm{ml}$ ) and POS-L (awake: $5.1 \pm 0.6 \mathrm{ng} / \mathrm{ml}$; $+30 \mathrm{~min}: 6.3 \pm 0.7 \mathrm{ng} / \mathrm{ml}+60 \mathrm{~min}: 4.4 \pm 0.6 \mathrm{ng} / \mathrm{ml}$ ) groups. Two-way repeated-measures ANOVA revealed the following values: for factor GROUP: $F(1,59)=3.415, p=0.081$; for factor TIME $F(2,59)=21.452, p<0.001$; for interaction GROUP x TIME $F(2,59)=9.157, p<0.001$.

The lower portion of Fig. 1 shows the mean levels \pm SE of salivary $\alpha$-amylase measured on the sampling day in the POS-H (awake: $25.5 \pm 4.4 \mathrm{U} / \mathrm{ml} ;+30 \mathrm{~min}: 38.6 \pm 3.9 \mathrm{U} / \mathrm{ml}$; $47.8 \pm 5.5 \mathrm{U} / \mathrm{ml}$ ) and POS-L (awake: $25.8 \pm 3.4 \mathrm{U} / \mathrm{ml} ;+30 \mathrm{~min}: 26.3 \pm 2.4 \mathrm{U} / \mathrm{ml} ; 25.8 \pm 1.7$ $\mathrm{U} / \mathrm{ml}$ ) groups. Two-way repeated-measures ANOVA revealed the following values: for factor GROUP: $F(1,59)=6.855 ; p=0.070$; for factor TIME $F(2,59)=8.123, p=0.001$; for interaction GROUP $\times$ TIME $F(2,59)=7.978, p=0.001$.

Confirming the stated hypotheses, both groups show a significant difference in the awakening responses for cortisol and $\alpha$-amylase associated with differences in the POS degree.

\subsection{AUCs for Salivary Cortisol and a-Amylase Awakening Responses in the Study Population}

Table 1 reports that the production of salivary cortisol at awakening is higher in the POS-H group than in the POS-L. In addition, there is a statistically significantly lower production of salivary $\alpha$-Amy in the POS-L group compared with the POS-H group upon awakening...

\section{Discussion}

Under basal nonchallenging conditions, the protocol of the present study provided a multiple-time-point assessment of salivary cortisol and $\alpha$-Amy production characterizing the activity of the HPA axis and SNS system in the first hour after waking in young healthy subjects with low and high POS scores. The main finding of this pilot study is that, compared to the POS-H group, the POS-L subjects presented a lower salivary CAR and a flattened $\alpha$-Amy production at 30 and 60 min after awakening.

In the present study, POS-H subjects showed a CAR higher than POS-L. The CAR, a sharp rise in cortisol levels in the first 30 min after awakening (Stalder et al. 2016), has been related to multiple psychosocial factors: both enhanced and reduced CARs are associated with various diseases (Chida and Steptoe 2009; Delle Chiaie et al. 2013; Kirschbaum et al. 1995), including depression and anxiety disorders (Bhattacharyya et al. 2008;

Table 1 AUCs for salivary cortisol and $\alpha$-amylase upon awakening in the study population

\begin{tabular}{llll}
\hline & POS-H $(n=10)$ & POS-L $(n=10)$ & Student $t$-test \\
\hline $\begin{array}{l}\text { Salivary } \\
\text { cortisol }\end{array}$ & $7.6 \pm 0.8$ & $5.5 \pm 0.6$ & $t=2.138, p=0.047$ \\
$\quad$ AUC (ng/ & & & \\
ml x h) & & $26.1 \pm 1.3$ & $t=2.738, p=0.014$ \\
Salivary & $37.6 \pm 4.0$ & & \\
$\begin{array}{l}\alpha \text {-amylase } \\
\text { AUC (U/ } \\
\text { ml x h) }\end{array}$ & & & \\
\hline
\end{tabular}

Data are shown as the mean values \pm SEM

$A U C$ Area under the curve of salivary biomarker production 
Vreeburg et al. 2010). Moreover, a reduced CAR has been described in subjects suffering from either posttraumatic stress disorder syndrome (Wessa et al. 2006) or fatigue-related symptoms (Nater et al. 2008). In addition, the CAR has been positively correlated with job stress and general life stress and negatively associated with fatigue, burnout, or exhaustion (Chida and Steptoe 2009). However, the relationship between the CAR and individual differences in personality features associated with POS, such as optimism, is less consistently evidenced. Research by Jobin and colleagues (2014) found that older people with low optimism had a lower CAR even if associated with higher daily cortisol production measured on the days when they reported higher stress. Low positive affect, assessed in a group of adult healthy men by ecological momentary assessment-derived ratings of happiness, was associated with higher cortisol early in the day and a heightened CAR (Steptoe et al. 2007). In contrast, studies with healthy older (Endrighi et al. 2011) and middle-aged adults (Lai et al. 2005) reported that high optimism was related to a lower CAR but not to cortisol decline over the day or total cortisol output. No relationship between the CAR and being an optimist or a pessimist was reported in healthy older people (Puig-Perez et al. 2018). To a large extent, such discrepancies may reflect methodological differences in the assessment of outcome and the heterogeneity of the population under study.

We hypothesized that POS-H and POS-L can be associated with distinct SAM system activity. Under basal nonchallenging conditions, we have found a flattened trajectory of salivary $\alpha$-Amy in the POS-L subjects during the first hour after awakening, which reflects a reduction in the SAM system activity. In contrast, the POS-H group showed significant physiological progressive diurnal increase in $\alpha$-Amy production (Ghiciuc et al. 2011).

In general, the human body maintains its physiological balance and responds to overall life requirements by counterbalancing the activities of the HPA axis and SAM system (Cortelli et al. 1994, 2012). Blunted levels of $\alpha$-Amy production, which were originally highlighted in the present study, are directly related to the dysregulation of the SAM system in the POS-L group and may affect individuals' psychosocial health (Cozma et al. 2017; Ghiciuc et al. 2013; McEwen 1998, 2006).

Showing different salivary cortisol and $\alpha$-Amy secretion patterns between POS-H and POS-L individuals, the current preliminary study suggested that POS-H subjects may benefit from an attitude towards life that enables them to better respond to external and/or internal stimuli and indirectly confirmed the previous hypothesis that views POS among personal assets that exert a protective function providing the necessary support to better face life adversities, failures, and losses (Caprara et al. 2009, 2016). These findings accord with the literature, which points to positivity as a key factor that contributes to success at work, within the family, and in society at large (Fredrickson and Losada 2005; Lyubomirsky et al. 2005; Pressman and Cohen 2005). Optimism is thought to be beneficial for health, and these effects may be mediated through modifications in psychophysiological stress reactivity (Puig-Perez et al. 2017).

The present report has several limitations worth noting. Only two small groups of students were enrolled in the salivary biomarker assay, though they were selected from a larger sample of 300 undergraduate medical faculty students on the basis of their extreme positivity level $\left(\leq 25^{\circ}\right.$ percentile and $\geq 75^{\circ}$ percentile). The extent to which our results might be generalized if the study were also extended to women and/or to a larger nonstudent population is unknown. Furthermore, since the sampling of saliva for biomarker measurement occurred only at awakening, the diurnal patterns need further exploration in larger samples.

We must also acknowledge, as a limitation of this study the possibility that participants may not have adhered properly to the protocol for the collection of salivary samples, 
although, in accordance with recently published guidelines, the exact saliva sampling schedule was described verbally by the recruiter to each participant and supplemented with detailed written instructions (Stalder et al. 2016). Therefore, recommendations to monitor adherence to the saliva sampling protocol contributed, in the present study, to the obtainment of valid cortisol and $\alpha$-Amy values for awakening responses. However, there is no way to know whether subjects correctly followed other instructions (e.g., refraining from eating, smoking, etc., in the hour before and during the saliva collection time points).

\section{Conclusions}

The original findings from this study are preliminary until they can be replicated with a larger population. Deepening the knowledge on the biological correlates of POS will help us determine the actions that need to be taken to improve individuals' assets.

Acknowledgements The study was financially supported by C26A11X8WX and C26A13STPW Sapienza University grants to GVC.

Funding Open access funding provided by Università degli Studi di Roma La Sapienza within the CRUICARE Agreement.

Open Access This article is licensed under a Creative Commons Attribution 4.0 International License, which permits use, sharing, adaptation, distribution and reproduction in any medium or format, as long as you give appropriate credit to the original author(s) and the source, provide a link to the Creative Commons licence, and indicate if changes were made. The images or other third party material in this article are included in the article's Creative Commons licence, unless indicated otherwise in a credit line to the material. If material is not included in the article's Creative Commons licence and your intended use is not permitted by statutory regulation or exceeds the permitted use, you will need to obtain permission directly from the copyright holder. To view a copy of this licence, visit http://creativecommons.org/licenses/by/4.0/.

\section{References}

Alessandri, G., Caprara, G. V., \& Tisak, J. (2012). The unique contribution of positive orientation to optimal functioning: further explorations. European Psychologist, 17(1), 44-45. https://doi.org/10.1027/10169040/a000070.

Alessandri, G., Borgogni, L., Schaufeli, W. B., Caprara, G. V., \& Consiglio, C. (2015). From positive orientation to job performance: the role of work engagement and self-efficacy beliefs. Journal of Happiness Studies, 16(3), 767-788. https://doi.org/10.1007/s10902-014-9533-4.

Baumeister, R. F., Campbell, J. D., Krueger, J. I., \& Vohs, K. D. (2003). Does high self-esteem cause better performance, interpersonal success, happiness, or healthier lifestyles? Psychological Science in the Public Interest, 4(1), 1-44.

Bhattacharyya, M. R., Molloy, G. J., \& Steptoe, A. (2008). Depression is associated with flatter cortisol rhythms in patients with coronary artery disease. Journal of Psychosomatic Research, 65(2), 107-113.

Bosch, J. A., Veerman, E. C., de Geus, E. J., \& Proctor, G. B. (2011). $\alpha$-Amylase as a reliable and convenient measure of sympathetic activity: don’t start salivating just yet! Psychoneuroendocrinology, 36(4), $449-453$.

Caprara, G. V., Alessandri, G., \& Barbaranelli, C. (2010a). Optimal functioning: contribution of self-efficacy beliefs to positive orientation. Psychotherapy and Psychosomatics, 79(5), 328-330. https://doi. org/10.1159/000319532.

Caprara, G. V., Alessandri, G., Trommsdorff, G., Heikamp, T., Yamaguchi, S., \& Suzuki, F. (2010b). Positive orientation across three cultures. Journal of Cross-Cultural Psychology, 43(1), 77-83. https://doi. org/10.1177/0022022111422257.

Caprara, G. V., Alessandri, G., Eisenberg, N., Kupfer, A., Steca, P., Caprara, M. G., \& Abela, J. (2012). The positivity scale. Psychological Assessment, 24(3), 701-712. https://doi.org/10.1037/a0026681. 
Caprara, G. V., Castellani, V., Alessandri, G., Mazzuca, F., La Torre, M., Barbaranelli, C., et al. (2016). Being positive despite illness: the contribution of positivity to the quality of life of cancer patients. Psychology \& Health, 31(5), 524-534. https://doi.org/10.1080/08870446.2015.1117081.

Caprara, G. V., Fagnani, C., Alessandri, G., Steca, P., Gignatesco, A., Cavalli Sforza, L. L., et al. (2009). Human optimal functioning: the genetics of positive orientation towards self, life, and the future. Behavior Genetics, 39(3), 277-284. https://doi.org/10.1007/s10519-009-9267-y.

Caprara, G. V., Nisini, R., Castellani, V., Pasquali, V., Guido, A., Ziparo, V., et al. (2017). Lymphocyte subsets are influenced by positivity levels in healthy subjects before and after mild acute stress. Immunology letters, 188, 13-20. https://doi.org/10.1016/j.imlet.2017.05.012.

Caprara, G. V., Steca, P., Alessandri, G., Abela, J. R. Z., \& McWhinnie, C. M. (2010c). Positive orientation: explorations on what is common to life satisfaction, self-esteem, and optimism. Epidemiologia e psichiatria sociale, 19(1), 63-71. https://doi.org/10.1017/S1121189X00001615.

Carver, C. S., Scheier, M. F., \& Segerstrom, S. C. (2010). Optimism. Clinical Psychology Review, 30(7), 879-889.

Chatterton, R. T., Jr., Vogelsong, K. M., Lu, Y. C., Ellman, A. B., \& Hudgens, G. A. (1996). Salivary alphaamylase as a measure of endogenous adrenergic activity. Clinical Physiology, 16(4), 433-448. https:// doi.org/10.1111/j.1475-097X.1996.tb00731.x.

Chida, Y., \& Steptoe, A. (2009). Cortisol awakening response and psychosocial factors: a systematic review and meta-analysis. Biological Psychology, 80(3), 265-278. https://doi.org/10.1016/j.biops ycho.2008.10.004.

Cortelli, P., Lombardi, C., Montagna, P., \& Parati, G. (2012). Baroreflex modulation during sleep and in obstructive sleep apnea syndrome. Autonomic Neuroscience, 169(1), 7-11. https://doi.org/10.1016/j. autneu.2012.02.005.

Cortelli, P., Parchi, P., Sforza, E., Contin, M., Pierangeli, G., Barletta, G., et al. (1994). Cardiovascular autonomic dysfunction in normotensive awake subjects with obstructive sleep apnoea syndrome. Clinical Autonomic Research, 4(1-2), 57-62. https://doi.org/10.1007/BF01828839.

Cozma, S., Dima-Cozma, L. C., Ghiciuc, C. M., Pasquali, V., Saponaro, A., \& Patacchioli, F. R. (2017). Salivary cortisol and $\alpha$-amylase: subclinical indicators of stress as cardiometabolic risk. Brazilian Journal of Medical and Biological Research, 50(2), e5577. https://doi.org/10.1590/1414-431X20165577.

Delle Chiaie, R., Trabucchi, G., Girardi, N., Marini, I., Pannese, R., Vergnani, L., et al. (2013). Group psychoeducation normalizes cortisol awakening response in stabilized bipolar patients under pharmacological maintenance treatment. Psychotherapy \& Psychosomatics, 82(4), 264-266. https://doi. org/10.1159/000348609.

Diener, E., Napa-Scollon, C. K., Oishi, S., Dzokoto, V., \& Suh, E. M. (2000). Positivity and the construction of life satisfaction judgments: global happiness is not the sum of its parts. Journal of Happiness Studies, 1(2), 159-176. https://doi.org/10.1023/A:1010031813405.

Endrighi, R., Hamer, M., \& Steptoe, A. (2011). Associations of trait optimism with diurnal neuroendocrine activity, cortisol responses to mental stress, and subjective stress measures in healthy men and women. Psychosomatic Medicine, 73(8), 672-678. https://doi.org/10.1097/PSY.0b013e31822f9cd7.

Fagnani, C., Medda, E., Stazi, M. A., Caprara, G. V., \& Alessandri, G. (2014). Investigation of age and gender effects on positive orientation in Italian twins. International Journal of Psychology, 49(6), 453461. https://doi.org/10.1002/ijop.12053.

Fekedulegn, D. B., Andrew, E. A., Burchfiel, C. M., Violanti, J. M., Hartley, T. A., Charles, L. E., et al. (2007). Area under the curve and other summary indicators of repeated waking cortisol measurements. Psychosomatic Medicine, 69(7), 651-659.

Fredrickson, B. L., \& Losada, M. F. (2005). Positive affect and the complex dynamics of human flourishing. The American Psychologist, 60(7), 678-686. https://doi.org/10.1037/0003-066X.60.7.678.

Ghiciuc, C. M., Cozma-Dima, C. L., Pasquali, V., Renzi, P., Simeoni, S., Lupusoru, C. E., et al. (2011). Awakening responses and diurnal fluctuations of salivary cortisol, DHEA-S and $\alpha$-amylase in healthy male subjects. Neuroendocrinology Letters, 32(4), 475-480.

Ghiciuc, C. M., Dima-Cozma, L. C., Bercea, R. M., Lupusoru, C. E., Mihaescu, T., Szalontay, A., et al. (2013). Restoring of salivary cortisol awakening response (CAR) by nasal continuous positive airway pressure (CPAP) therapy in obstructive sleep apnea. Chronobiology International, 30(8), 124-131. https://doi.org/10.3109/07420528.2013.795155.

Gröschl, M., Khöler, H., Topf, H. G., Rupprecht, T., \& Rauh, M. (2008). Evaluation of saliva collection devices for the analysis of steroids, peptides and therapeutic drugs. Journal of Pharmaceutical and Biomedical Analysis, 47(3), 478-486. https://doi.org/10.1016/j.jpba.2008.01.033.

Hackney, A. C., \& Viru, A. (2008). Research methodology: endocrinology measurements in exercise science and sports medicine. Journal of Athletic Training, 43(6), 631-639. 
Hanrahan, K., McCarthy, A. M., Kleiber, C., Lutgendorf, S., \& Tsalikian, E. (2006). Strategies for salivary cortisol collection and analysis in research with children. Applied Nursing Research, 19(2), 95-101. https://doi.org/10.1016/j.apnr.2006.02.001.

Jobin, J., Wrosch, C., \& Scheier, M. F. (2014). Associations between dispositional optimism and diurnal cortisol in a community sample: when stress is perceived as higher than normal. Journal of Health Psychology, 33(4), 382-391. https://doi.org/10.1037/a0032736.

Kirschbaum, C., Kudielka, B. M., Gaab, J., Schommer, N. C., \& Hellhammer, D. H. (1999). Impact of gender, menstrual cycle phase, and oral contraceptives on the activity of the hypothalamus-pituitaryadrenal axis. Psychosomatic Medicine, 61(2), 154-162. https://doi.org/10.1097/00006842-19990300000006.

Kirschbaum, C., Prüssner, J. C., Stone, A. A., Federenko, I., Gaab, J., Lintz, D., et al. (1995). Persistent high cortisol responses to repeated psychological stress in a subpopulation of healthy men. Psychosomatic Medicine, 57(5), 468-474. https://doi.org/10.1097/00006842-199509000-00009.

Lai, J. C., Evans, P. D., Ng, S. H., Chong, A. M., Siu, O. T., Chan, C. L., et al. (2005). Optimism, positive affectivity, and salivary cortisol. British Journal of Health Psychology, 10(Pt 4), 467-484. https://doi.org/10.1348/135910705X26083.

Li, T. L., \& Gleeson, M. (2004). The effect of single and repeated bouts of prolonged cycling and circadian variation on saliva flow rate, immunoglobulin A and alpha-amylase responses. Journal of Sports Sciences, 22(11-12), 1015-1024. https://doi.org/10.1080/02640410410001716733.

Lyubomirsky, S., King, L., \& Diener, E. (2005). The benefits of frequent positive affect: does happiness lead to success? Psychological Bulletin, 131(6), 803-855. https://doi. org/10.1037/0033-2909.131.6.803.

McEwen, B. S. (1998). Protective and damaging effects of stress mediators. The New England Journal of Medicine, 338(3), 171-179.

McEwen, B. S. (2006). Protective and damaging effects of stress mediators: central role of the brain. Dialogues in Clinical Neuroscience, 8(4), 367-381.

Nater, U. M., \& Rohleder, N. (2009). Salivary alpha-amylase as a non-invasive biomarker for the sympathetic nervous system: current state of research. Psychoneuroendocrinology, 34(4), 486-496. https ://doi.org/10.1016/j.psyneuen.2009.01.014.

Nater, U. M., Hoppmann, C. A., \& Scott, S. B. (2013). Diurnal profiles of salivary cortisol and alphaamylase change across the adult lifespan: evidence from repeated daily life assessments. Psychoneuroendocrinology, 38(12), 3167-3171. https://doi.org/10.1016/j.psyneuen.2013.09.008.

Nater, U. M., La Marca, R., Florin, L., Moses, A., Langhans, W., Koller, M. M., et al. (2006). Stress induced changes in human salivary alpha-amylase activity associations with adrenergic activity. Psychoneuroendocrinology, 31(1), 49-58. https://doi.org/10.1016/j.psyneuen.2005.05.010.

Nater, U. M., Rohleder, N., Schlotz, W., Ehlert, U., \& Kirschbaum, C. (2007). Determinants of the diurnal course of salivary alpha-amylase. Psychoneuroendocrinology, 32(4), 392-401. https://doi. org/10.1016/j.psyneuen.2007.02.007.

Nater, U. M., Youngblood, L. S., Jones, J. F., Unger, E. R., Miller, A. H., Reeves, W. C., et al. (2008). Alterations in diurnal salivary cortisol rhythm in a population-based sample of cases with chronic fatigue syndrome. Psychosomatic Medicine, 70(3), 298-305. https://doi.org/10.1097/PSY.0b013e3181651025.

Patacchioli, F. R., Ghiciuc, C. M., Bernardi, M., Dima-Cozma, L. C., Fattorini, L., Squeo, M. R., et al. (2015). Salivary $\alpha$-amylase and cortisol after exercise in menopause: influence of long-term HRT. Climacteric, 20(4), 1-20. https://doi.org/10.3109/13697137.2015.1008444.

Pavot, W., \& Diener, E. (2008). The satisfaction with life scale and the emerging construct of life satisfaction. The Journal of Positive Psychology, 3(2), 137-152. https://doi.org/10.1080/17439760701756946.

Pressman, S. D., \& Cohen, S. (2005). Does positive affect influence health? Psychological Bulletin, 131(6), 925-971. https://doi.org/10.1037/0033-2909.131.6.925.

Proulx, J., Klee, D., \& Oken, B. S. (2017). Do psychosocial predictors affect the following days' cortisol awakening response? Expanding the temporal frame with which to explore morning cortisol. Stress, 20(4), 398-403. https://doi.org/10.1080/10253890.2017.1346076.

Pruessner, J. C., Kirschbaum, C., Meinlschmid, G., \& Hellhammer, D. H. (2003). Two formulas for computation of the area under the curve represent measures of total hormone concentration versus time-dependent change. Psychoneuroendocrinology, 28(7), 916-931. https://doi.org/10.1016/S0306 $-4530(02) 00108-7$.

Pruessner, J. C., Wolf, O. T., Hellhammer, D. H., Buske-Kirschbaum, A., von Auer, K., Jobst, S., et al. (1997). Free cortisol levels after awakening: a reliable biological marker for the assessment of adrenocortical activity. Life Sciences, 61(26), 2539-2549. https://doi.org/10.1016/S0024-3205(97)01008-4. 
Puig-Perez, S., Hackett, R. A., Salvador, A., \& Steptoe, A. (2017). Optimism moderates psychophysiological responses to stress in older people with Type 2 diabetes. Psychophysiology, 54(4), 536-543. https://doi.org/10.1111/psyp.12806.

Puig-Perez, S., Pulopulos, M. M., Hidalgo, V., \& Salvador, A. (2018). Being an optimist or a pessimist and its relationship with morning cortisol release and past life review in healthy older people. Psychology \& Health, 33(6), 783-799. https://doi.org/10.1080/08870446.2017.1408807.

Scheier, M. F., \& Carver, C. S. (1992). Effects of optimism on psychological and physical well-being: theoretical overview and empirical update. Cognitive Therapy and Research, 16(2), 201-228. https ://doi.org/10.1007/BF01173489.

Schumacher, S., Kirschbaum, C., Fydrich, T., \& Ströhle, A. (2013). Is salivary alpha-amylase an indicator of autonomic nervous system dysregulations in mental disorders? - a review of preliminary findings and the interactions with cortisol. Psychoneuroendocrinology, 38(6), 729-743. https://doi. org/10.1016/j.psyneuen.2013.02.003.

Seligman, M. E. P., \& Csikszentmihalyi, M. (2000). Positive psychology: an introduction. American Psychologist, 55(1), 5-14. https://doi.org/10.1037/0003-066X.55.1.5.

Simeoni, S., Biselli, R., D’Amelio, R., Rocca, B., Lattanzio, S., Mucci, L., et al. (2011). Stress-induced salivary cortisol secretion during hypobaric-hypoxia challenge and in vivo urinary thromboxane production in healthy male subjects. Stress, 14(3), 282-289. https://doi.org/10.3109/10253890.2010.545458.

Stalder, T., Kirschbaum, C., Kudielka, B. M., Adam, E. K., Pruessner, J. C., Wüst, S., et al. (2016). Assessment of the cortisol awakening response: expert consensus guidelines. Psychoneuroendocrinology, 63, 414-432. https://doi.org/10.1016/j.psyneuen.2015.10.010.

Steptoe, A., Gibson, E. L., Hamer, M., \& Wardle, J. (2007). Neuroendocrine and cardiovascular correlates of positive affect measured by ecological momentary assessment and by questionnaire. Psychoneuroendocrinology, 32(1), 56-64. https://doi.org/10.1016/j.psyneuen.2006.10.001.

Vreeburg, S. A., Hoogendijk, W. J., van Pelt, J., Derijk, R. H., Verhagen, J. C., van Dick, R., et al. (2009). Major depressive disorder and hypothalamic-pituitary-adrenal axis activity: results from a large cohort study. Archives of General Psychiatry, 66, 617-626.

Vreeburg, S. A., Zitman, F. G., van Pelt, J., Derijk, R. H., Verhagen, J. C., van Dyck, R., et al. (2010). Salivary cortisol levels in persons with and without different anxiety disorders. Psychosomatic Medicine, 72(4), 340-347. https://doi.org/10.1097/PSY.0b013e3181d2f0c8.

Wessa, M., Rohleder, N., Kirschbaum, C., \& Flor, H. (2006). Altered cortisol awakening response in posttraumatic stress disorder. Psychoneuroendocrinology, 31(2), 209-215. https://doi.org/10.1016/j.psyne uen.2005.06.010.

Wolf, J. M., Nicholls, E., \& Chen, E. (2008). Chronic stress, salivary cortisol, and alpha-amylase in children with asthma and healthy children. Biological Psychology, 78(1), 20-28. https://doi.org/10.1016/j.biops ycho.2007.12.004.

Yamaguchi, M., Deguchi, M., Wakasugi, J., Ono, S., Takai, N., Higashi, T., et al. (2006). Hand-held monitor of sympathetic nervous system using salivary amylase activity and its validation by driver fatigue assessment. Biosensors and Bioelectronics, 21(7), 1007-1014. https://doi.org/10.1016/j. bios.2005.03.014.

Yumuk, V., Tsigos, C., Fried, M., Schindler, K., Busetto, L., Micic, D., et al. (2015). European guidelines for obesity management in adults. Obesity Facts, 8(6), 402-424. https://doi.org/10.1159/000442721.

Publisher's Note Springer Nature remains neutral with regard to jurisdictional claims in published maps and institutional affiliations.

\section{Affiliations}

\section{Vittorio Pasquali ${ }^{1}$ (D) Cristina Mihaela Ghiciuc ${ }^{2}$. Valeria Castellani ${ }^{1}$. Gian Vittorio Caprara ${ }^{1}$. Guido Alessandri ${ }^{1}$. Raffaele D'Amelio ${ }^{3}$. Vincenzo Ziparo ${ }^{4}$. Fabio Scarinci ${ }^{5}$. Francesca Romana Patacchioli ${ }^{5,6}$}

Vittorio Pasquali

vittorio.pasquali@uniroma1.it

1 Department of Psychology, Sapienza University of Rome, Rome, Italy 
2 Department of Pharmacology, School of Medicine, University of Medicine and Pharmacy "Grigore T. Popa", Iasi, Romania

3 Department of Clinical and Molecular Medicine, Sapienza University of Rome, Rome, Italy

4 Department of Medical and Surgical Sciences and Translational Medicine, Sapienza University of Rome, Rome, Italy

5 IRCCS - Fondazione Bietti, Rome, Italy

6 Department of Physiology and Pharmacology "V. Erspamer", Sapienza University of Rome, Rome, Italy 